\title{
LA INMEDIACIÓN A LA LUZ DEL CONVENIO EUROPEO DE DERECHOS HUMANOS. EL CASO DE ESPAÑA
}

\section{IMMEDIACY IN THE LIGHT OF THE EUROPEAN CONVENTION ON HUMAN RIGHTS. THE SPANISH CASE}

\author{
Ignacio ÁLVAREZ RODRÍGUEZ*
}

Recibido: 06/01/2019

Aceptado: 09/04/2019

SUMARIO: I. Introducción. II. La inmediación como garantía: aspectos generales. III La inmediación como garantía en el Convenio Europeo de Derechos Humanos. IV. Las condenas a España por vulnerar la inmediación en la segunda instancia penal. V. La reacción de España ante las condenas. VI. Conclusiones. 7. Bibliografía.

SUMMARY: I. Introduction. II. Immediacy as a guarantee: general aspects. III. Immediacy as a guarantee in the European Convention on Human Rights. IV. The negative sentences to Spain for violating the immediacy in the second criminal instance. V. Spain's reaction to the sentences. VI. Conclusions. VII. Bibliography.

Palabras clave: Inmediación, Convenio Europeo de Derechos Humanos, Tribunal Europeo de Derechos Humanos, España.

Resumen: El presente texto estudia la garantía de inmediación en el marco del Convenio Europeo de Derechos Humanos, garantía deducida del artículo 6 por parte del Tribunal Europeo de Derechos Humanos, con especial referencia al caso de España. Para ello se aborda unas nociones generales de lo que es el principio de inmediación. A partir de ahí se estudia dicha garantía en el marco del Convenio Europeo de Derechos Humanos, con especial referencia al caso de España y a las condenas dictadas por el Tribunal Europeo de Derechos Humanos. Finalmente, se expone la reacción de las autoridades españolas ante tales condenas, así como los debates doctrinales que han tenido lugar y las reformas legales pertinentes.

Abstract: The text studies the immediacy guarantee within the European Convention on Human Rights, given by article 6, in accordance to the European Court of Human Rights interpretation, specifically focusing on the Spanish case. Firstly, we study the principle/guarantee of immediacy in a general way. Secondly, we study that guarantee within the European Convention on Human Rights and the judgments were our country is condemned by the European Court on Human Rights. Finally, we give some evidence about the answer given by national authorities to solve the problem, specifically within the expertise debate and the legal reforms put into force.

Key words: Immediacy, European Convention on Human Rights, European Court of Human Rights, Spain. 


\section{I.- INTRODUCCIÓN}

En el presente trabajo ${ }^{1}$ se ofrece un estudio acerca de las condenas impuestas por el Tribunal Europeo de Derechos Humanos al Reino de España por vulnerar la garantía de inmediación en la segunda instancia penal².

Para ello se explica, en primer lugar, unas nociones generales y necesariamente breves acerca de la garantía de inmediación; en segundo lugar, se estudia con detalle las condenas impuestas a nuestro país por vulnerar dicha garantía; en tercer lugar, se expone cuáles han sido las actitudes en forma de reacción respecto a tres instancias (nuestra comunidad de expertos, nuestros altos tribunales y nuestro legislador). Finalmente, se comparte algunas reflexiones finales a modo de conclusión.

\section{LA INMEDIACIÓN COMO GARANTÍA: ASPECTOS GENERALES}

En este apartado se va a prestar atención a tres aspectos. En primer término, se abordará el concepto y la propia noción de inmediación, especialmente en su significado jurídico-procesal. En segundo término, se prestará atención a los argumentos que destacan la relevancia e importancia que se le suele otorgar en el ámbito de nuestro Derecho Procesal. Finalmente, en tercer lugar, se expondrá su inclusión como garantía procesal constitucional deducible del artículo $24 \mathrm{CE}$, así como garantía legal incardinada tanto en la legislación general como en la específicamente civil y penal.

La inmediación es un principio procesal según el cual los jueces y magistrados integrantes del tribunal, y respecto de aquellas funciones jurisdiccionales que le son propios, deben estar presentes en la práctica de las pruebas y en cualquier otro acto que

\footnotetext{
* Profesor Ayudante Doctor de Derecho Constitucional. Universidad Complutense de Madrid. Correo electrónico: ialvarez1@ucm.es El autor desea agradecer especialmente al personal de las Biblioteca de la Facultad de Ciencias Sociales, Jurídicas, y de la Comunicación de la Universidad de Valladolid (Campus de Segovia), así como al personal de la Biblioteca de la Facultad de Derecho de la Universidad Complutense de Madrid, su eficaz ayuda a la hora de localizar diversos materiales bibliográficos para elaborar el presente texto. Además, tampoco quiere olvidar la ayuda y consejos que le prestaron D. Ignacio Torres Muro; D. José Manuel Chozas Alonso; y D. ${ }^{a}$ María Luisa Escalada López. Huelga decir que todo error u omisión que se aprecie es únicamente imputable al arriba firmante. Por lo demás, el trabajo se enmarca en el Proyecto de Investigación DER2016-75993-P, sobre España ante Europa: retos nacionales en materia de derechos humanos (30/12/2016-29/12/2020). IP: Francisco Javier MATIA PORTILLA.

${ }^{2}$ Aunque relacionada con el objeto del presente trabajo, la generalización de la segunda instancia penal presenta algunos contornos concretos que obligan a un tratamiento específico, en todo caso desbordando las modestas capacidades del autor y el objeto de estas líneas. Baste decir de forma muy resumida que España ha reformado recientemente la legislación procesal penal para dar cabida a una exigencia internacional que data de muy antiguo y que se incardina en el artículo 14.5 PIDCP. Vid. MARCHENA GÓMEZ, Manuel; y GONZÁLEZ-CUÉLLAR SERRANO, Nicolás: La reforma de la Ley de Enjuiciamiento Criminal en 2015. Ediciones Jurídicas Castillo de Luna. Madrid, 2015, p. 533 y ss; BELLIDO PENADÉS, Rafael: "Generalización de la segunda instancia y apertura de la casación en el Proyecto de reforma de la Ley de Enjuiciamiento Criminal de 2015". Diario La Ley, $n^{o}$ 8619, (2015); y "Revisión penal y generalización de la doble instancia penal en el proyecto de reforma de la LECrim. de 2015", Diario La Ley no 8526, 2015; ALCÁCER GUIRAO, Rafael: El derecho a una segunda instancia con todas las garantías. Tirant lo blanch. Valencia, 2013; y TAPIA FERNÁNDEZ, Isabel: La implantación generalizada de la segunda instancia penal. Presente y futuro. Civitas-Thomson Reuters. Cizur Menor, 2011.
} 
deba llevarse a cabo contradictoria y públicamente ${ }^{3}$. La inmediación no deja de ser, pues, la ventaja que tiene el juez de poder valorar debidamente las pruebas que ante él se practiquen, para disponer de todos los elementos posibles a la hora de acometer la tarea de juzgar ${ }^{4}$. Por lo demás, dicha ventaja se materializa fundamentalmente a través de la presencia física del juzgador, lo cual, tal y como ha destacado la doctrina, acerca la figura con otros institutos procesales como la oralidad y la contradicción ${ }^{5}$.

Qué duda cabe que la inmediación, tal y como sucede con la contradicción o la oralidad, tiene una importancia capital en la prueba. Y lo tiene al menos en un doble sentido, subjetivo y objetivo. En el sentido subjetivo porque implica que el mismo juez entra en contacto directo con el objeto del proceso; y en sentido objetivo porque el juez adquiere convicción sobre el objeto en sí mismo considerado. Por eso la consecuencia lógica que se infiere es que sólo puede dictar sentencia el juez que efectivamente presencie la práctica de la prueba. Y por eso no tiene mucho sentido hablar de inmediación en la fase de instrucción y sí en la de juicio oral ${ }^{6}$. Desde luego que la idea de realizar las actuaciones ante el juez, especialmente las probatorias, sólo tiene realmente sentido si nos movemos en el marco de un proceso regido por el principio acusatorio (y no por el inquisitivo), donde las partes comparecen ante un tercero imparcial, en pie de igualdad y con contradicción plena, para que este resuelva el litigio conforme al Derecho objetivo ${ }^{7}$.

Es de justicia reconocer que no todos los autores se muestran igual de convencidos de las bondades de la inmediación. Las principales críticas vertidas aluden a cierta magnificación y sobrevaloración de la misma, por cuanto se quiere hacer pasar por criterios objetivos lo que tiene más que ver con cuestiones relacionadas con la intuición y/o la tradición ${ }^{8}$. Si eso se lleva a la valoración de las pruebas más problemáticas, como lo son las declaraciones personales de testigos y/o acusados, y siguiendo de nuevo a este sector, resultaría incierto sostener que su correcta observancia

\footnotetext{
${ }^{3}$ Vid. MUÑOZ MACHADO, Santiago (dir): "Principio de inmediación". Diccionario Panhispánico del Español Jurídico, Real Academia Española-Santillana. Madrid, 2017, p. 1591; y SÁNCHEZ ROMERO, Rosario: La garantía jurisdiccional de inmediación en la segunda instancia penal. Dykinson. Madrid, 2017, p. 24 y ss.

${ }^{4}$ Vid. MAGRO SERVET, Vicente: "Inmediación". En Arnaldo Alcubilla, Enrique (coord.): Enciclopedia Jurídica La Ley. Wolters Kluwer. Las Rozas, 2008-2009, p. 9716.

${ }^{5}$ Vid. MONTOYA MELGAR, Alfredo (dir): Diccionario Jurídico. Thomson Reuters Aranzadi. Cizur Menor, 2016, p. 621. Para Goldschmidt lo que diferencia la inmediación de la oralidad es que "la oralidad es una forma del entendimiento, la inmediatividad es un escalón de la percepción". Vid. GOLDSCHMIDT, James: Problemas jurídicos y políticos del proceso penal. Euros Editores. Buenos Aires, 2016, p. 95 (1 $1^{\text {a }}$ edición, Editorial Bosch, Barcelona, 1935).

${ }^{6}$ Vid. MORENO CATENA, Víctor; y CORTÉS DOMÍNGUEZ, Valentín: Derecho Procesal Penal. Tirant lo blanch. Valencia, 2017, p. 419 y ss.

${ }^{7}$ La doctrina llegó a la convicción hace mucho tiempo de que el llamado proceso inquisitivo no es en realidad un proceso que merezca tal nombre; que "proceso" es una categoría que solo puede aplicarse al proceso acusatorio. Por eso "la asunción del monopolio de la actuación del Derecho penal por los órganos jurisdiccionales y la exclusividad en su ejercicio" es la mejor de las garantías; el proceso es, en puridad, una auténtica conquista de la civilización. Así lo expone MONTERO AROCA, Juan: Principios del proceso penal. Una explicación basada en la razón. Tirant lo blanch. Valencia, 1997, p. 28 y ss.

${ }^{8}$ En este preciso sentido, ver RIFÁ SOLER, José María; y RICHARD GONZÁLEZ, Manuel: El Proceso Penal Práctico. Wolters Kluwer. Las Rozas, 2017, p. 1233 y ss.
} 
pende exclusivamente de la inmediación. Por el sencillo motivo de que "el juez no puede saber a ciencia cierta si el declarante miente o dice la verdad" ${ }^{9}$.

Aunque no aparece explícitamente en el texto literal de la Norma, la interpretación constante y continuada del Juez de la Constitución ha situado la inmediación como un instituto procesal inherente al derecho fundamental a un proceso con todas las garantías del artículo $24 \mathrm{CE}^{10}$. Huelga decir que no es óbice para observar esta garantía el hecho de que nuestra Norma fundamental no la reconozca expresamente $^{11}$. El Tribunal Constitucional, como luego se verá con más detalle, ha deducido la inmediación de dicho precepto en diversas ocasiones, en jurisprudencia constante y reiterada cuya última muestra es, hasta la fecha de cierre del presente, la STC 59/2018, de 4 de junio. Conviene recordar la importancia de la que goza en esta materia la no indefensión del justiciable, incardinada en el precepto constitucional referido ${ }^{12}$.

A nivel legal, la garantía de inmediación se regula tanto en la legislación general como en la procesal penal y en la procesal civil. Así, por ejemplo, en el artículo 229.2 LOPJ, donde se dice que "las declaraciones, interrogatorios, testimonios, careos, exploraciones, informes, ratificación de los periciales y vistas, se llevarán a efecto ante juez o tribunal con presencia o intervención, en su caso, de las partes y en audiencia pública, salvo lo dispuesto en la ley". Otro tanto sucede en la legislación procesal penal. Sin ir más lejos, el propio artículo 683 LECrim establece que "el Presidente dirigirá los debates cuidando de impedir las discusiones impertinentes y que no conduzcan al esclarecimiento de la verdad, sin coartar por esto a los defensores la libertad necesaria para la defensa". Lo mismo se aprecia en la legislación procesal civil. Así, en el Capítulo III LEC, concretamente en su artículo 137: "1. Los Jueces y los Magistrados miembros del tribunal que esté conociendo de un asunto presenciarán las declaraciones de las partes y de testigos, los careos, las exposiciones, explicaciones y respuestas que hayan de ofrecer los peritos, así como la crítica oral de su dictamen y cualquier otro acto de prueba que, conforme a lo dispuesto en esta Ley, deba llevarse a cabo contradictoria y públicamente. 2. Las vistas y las comparecencias que tengan por objeto oír a las partes antes de dictar una resolución se celebrarán siempre ante el Juez o los Magistrados integrantes del tribunal que conozca del asunto"13.

De este brevísimo repaso puede deducirse, tal y como se decía antes, que la inmediación es una garantía procesal que se encuentra desde hace muchos años entre

\footnotetext{
${ }^{9}$ Vid. NIEVA FENOLL, Jordi: La ciencia jurisdiccional: novedad y tradición. Marcial Pons. Madrid, 2016, p. 304 y ss. Cfr. ANDRÉS IBÁÑEZ, Perfecto: "Sobre el valor de la inmediación (una aproximación crítica)". Jueces para la democracia, $n^{\circ}$ 46, 2003, pp. 57-66.

${ }^{10}$ Que reza así: "Asimismo, todos tienen derecho al Juez ordinario predeterminado por la ley, a la defensa y a la asistencia de letrado, a ser informados de la acusación formulada contra ellos, a un proceso público sin dilaciones indebidas y con todas las garantías, a utilizar los medios de prueba pertinentes para su defensa, a no declarar contra sí mismos, a no confesarse culpables y a la presunción de inocencia".

${ }^{11}$ En ese sentido GARBERí LLOBREGAT, José: Constitución y Derecho Procesal. Civitas. Cizur Menor, 2009, p. 326.

${ }^{12}$ Vid. CARRASCO DURÁN, Manuel: El derecho a la tutela judicial efectiva sin indefensión. Aranzadi. Cizur Menor, 2018; y RUIZ-RICO RUIZ, Gerardo; y CARAZO LIÉBANA, María José: El derecho a la tutela judicial efectiva, Tirant lo Blanch, Valencia, 2013.

${ }^{13}$ Para el ámbito que interesa al objeto del presente texto véase RIFÁ SOLER, José María; y RICHARD GONZÁLEZ, Manuel: El Proceso..., cit., p. 1233 y ss. Para el proceso civil puede verse BOTELLA SORIA, Enrique J.: "Las vulneraciones del principio de inmediación en la segunda instancia del proceso civil. Posibles soluciones". Proceso civil: cuaderno jurídico, $n^{\circ}$ 131, 2018, pp. 18-28.
} 
nosotros y así permanece en la actualidad, siempre tratada con la sana crítica correspondiente por parte de la comunidad de expertos ${ }^{14}$.

\section{LA INMEDIACIÓN COMO GARANTÍA EN EL SISTEMA DEL CONVENIO EUROPEO DE DERECHOS HUMANOS}

Repasadas concisamente esas breves generalidades sobre la inmediación en nuestro ordenamiento ahora se hará lo propio con dicho instituto en el sistema del CEDH. En primer lugar, se expondrá su recepción en el mismo, en el marco del artículo 6, y las implicaciones que de él se derivan. En segundo lugar, se aborda la interpretación que ha hecho el TEDH del mismo desde una perspectiva general. En tercer lugar, se hace otro tanto con las diferentes condenas que este ha dictado contra el Reino de España por vulnerar, precisamente, la garantía de inmediación en la segunda instancia penal.

De igual modo que sucede con nuestra Constitución, y también respecto a lo que ocurre con algún que otro ejemplo comparado, el texto del Convenio no regula explícitamente la inmediación. Esta garantía ha sido deducida por diversa jurisprudencia del TEDH en el marco del llamado derecho al proceso debido/derecho a un juicio justo, este sí regulado expresamente en el artículo 6.1 $\mathrm{CEDH}^{15}$.

El derecho al proceso debido es una de las llamadas leading-norms. Su importancia queda demostrada si tenemos en cuenta que hablamos del precepto más alegado ante la jurisdicción de Estrasburgo, amén de ser el que más sentencias ha producido hasta la fecha ${ }^{16}$.

\footnotetext{
${ }^{14}$ En suma: su principal ventaja "es la (...) participación activa del juez durante la práctica de la prueba, que permite que la motivación de las sentencias sea perfectamente explicable, al haber adquirido el juez, previo debate con las partes, razones verdaderamente tangibles en las que basar sus inferencias (...)". Siempre teniendo en cuenta que [la inmediación] "no puede convertirse en un mecanismo para evitar la recurribilidad de las sentencias. Bien al contrario, debe ser la clave para favorecer dicha recurribilidad, con la mejor adquisición de la convicción por parte del juez en la forma referida, y con su mejor motivación". Tales razonamientos son de NIEVA-FENOLL, Jordi: "Oralidad e Inmediación en la prueba: luces y sombras". En Civil Procedure Review, vol. 1-2, 2010, p. 41.

${ }^{15}$ Que reza así: "Toda persona tiene derecho a que su causa sea oída equitativa, públicamente y dentro de un plazo razonable, por un tribunal independiente e imparcial, establecido por la ley, que decidirá los litigios sobre sus derechos y obligaciones de carácter civil o sobre el fundamento de cualquier acusación en materia penal dirigida contra ella. La sentencia debe ser pronunciada públicamente, pero el acceso a la sala de audiencia puede ser prohibido a la prensa y al público durante la totalidad o parte del proceso en interés de la moralidad, del orden público o de la seguridad nacional en una sociedad democrática, cuando los intereses de los menores o la protección de la vida privada de las partes en el proceso así lo exijan o en la medida considerada necesaria por el tribunal, cuando en circunstancias especiales la publicidad pudiera ser perjudicial para los intereses de la justicia". Para ver un análisis comparado de lo que sucede en diversos países respecto a este y otros preceptos del CEDH puede consultarse MATIA PORTILLA, Francisco Javier; y ÁLVAREZ RODRÍGUEZ, Ignacio (dirs.): Informes Nacionales Europeos sobre el Tribunal Europeo de Derechos Humanos (Alemania, España, Francia, Italia, Polonia). Tirant lo blanch, Valencia, 2018. Estudia las particularidades de este derecho en el sistema convencional MILIONE, C; El derecho a la tutela judicial efectiva en la jurisprudencia del Tribunal Europeo de Derechos Humanos, Tirant lo Blanch, Valencia, 2015.

${ }^{16}$ Vid. ESPARZA LEIBAR, Iñaki; y ETXEBARRÍA GURIDI, José Francisco; "Derecho a un proceso equitativo". En LASAGABASTER HERRARTE, Iñaki (dir.): Convenio Europeo de Derechos Humanos: Comentario Sistemático. Civitas. Madrid, 2015 (3 edición), pp. 264 y ss; VIDAL ZAPATERO, José Miguel: "El derecho a un proceso público". En García Roca, Javier; y Santolaya Machetti, Pablo; (coords): La Europa de los Derechos. El Convenio Europeo de Derechos Humanos. CEPC. Madrid, 2014
} 
Lo primero que cabe destacar de la exégesis general que ha realizado el TEDH es que la interpretación de lo que engloba el derecho a un proceso equitativo es más amplia que la que realizan las diferentes jurisdicciones de los Estados miembros, propiciando la creación jurisprudencial de principios que no resultan de manera explícita del texto, como se verá a continuación.

Tampoco conviene olvidar que el TEDH ha sentado en no pocas ocasiones que los Estados disponen de un amplio margen de actuación a la hora de adoptar los medios y remedios procesales y judiciales que estimen oportunos. Es sabido que la jurisdicción de Estrasburgo ni es una cuarta instancia, ni una casación internacional, ni "revisa la bondad o justeza de las resoluciones jurisdiccionales nacionales": sólo conoce de los casos de forma subsidiaria y, cuando lo hace, no lo hace tanto para entrar a conocer de los errores cometidos en los procesos internos sino porque "algo que ha sucedido" en esos procesos no ha respetado las previsiones del Convenio ${ }^{17}$.

Por lo demás el artículo 6.1 CEDH reconoce en su interior diversos derechos, subsumibles en uno: el derecho al proceso debido, que a su vez tiene dos manifestaciones clave, el principio de contradicción y el principio procesal de igualdad de armas. Ambas garantías son especialmente importantes en el proceso penal, por motivos obvios. En su formulación tradicional, el primero supone que nadie puede ser condenado sin ser oído y vencido antes en juicio. El segundo garantiza, por su parte, la capacidad de todas las partes para que puedan participar en el conjunto de actuaciones procesales. En lo que aquí interesa también hay que recordar el principio de publicidad, especialmente relevante en la jurisdicción penal toda vez que es una garantía adicional no ya para que el Tribunal establezca la verdad -que también- sino para que se pueda fiscalizar el desempeño independiente e imparcial de este ${ }^{18}$.

En lo que hace a las sucesivas instancias donde se puede desarrollar ese proceso debido, en primera instancia implica que el acusado pueda asistir a todos los debates públicos. En lo que hace a la segunda y restantes instancias (apelación, casación, amparo), habrá que estar a las particularidades del proceso, lo cual, como ya se dijo arriba, entra dentro del margen de apreciación nacional ${ }^{19}$.

Y dentro de este marco, ¿qué ha dicho el TEDH sobre el principio de inmediación? Lo principal ha sido el establecimiento de una regla general, al menos desde finales de la década de los setenta del pasado siglo: el artículo 6.1 CEDH reconoce las mismas garantías tanto en el proceso de instancia como en el proceso de apelación ${ }^{20}$. Por ello dicha apelación debe celebrarse en audiencia pública, escuchando de nuevo a las partes $\mathrm{y}$, especialmente, al acusado, quien debe estar presente en los

( $3^{\text {a }}$ edición), p. 265 y ss; y ALCÁCER GUIRAO, Rafael; El derecho a una segunda instancia con todas las garantías, Tirant lo blanch, Valencia, 2013.

${ }^{17}$ Vid. CASADEVALL, Josep: El Convenio Europeo de Derechos Humanos, el Tribunal de Estrasburgo y su Jurisprudencia. Tirant lo blanch. Valencia, 2012, p. 273 y ss.

${ }^{18}$ Vid. ESPARZA LEIBAR, Iñaki; y ETXEBARRÍA GURIDI, José Francisco: "Derecho...", cit. p. 264 y ss.

19 Sobre el mismo véase GARCÍA ROCA, Javier: El margen de apreciación nacional en la interpretación del Convenio Europeo de Derechos Humanos: soberanía e integración, Cuadernos Civitas. Thomson Reuters, Cizur Menor, 2010; y ALGUACIL GONZÁLEZ-AURIOLES, J; "Ponderación, proporcionalidad y margen de apreciación en la jurisdicción europea de los derechos". Revista General de Derecho Europeo, $n^{\circ} 25,2011$, pp. 1-18.

${ }^{20}$ STEDH Delcourt c. Bélgica, de 17 de enero de 1970. 
debates $^{21}$. Aun más, en apelación es obligado escuchar los testimonios personales de los acusados directamente si lo que hace el tribunal ad quem es condenar cuando el tribunal a quo absolvió, o si agrava la condena impuesta en instancia ${ }^{22}$. El criterio completo sería el siguiente: si el tribunal de apelación realiza una nueva valoración de elementos fácticos y de dicha valoración se deduce una condena al acusado cuando el tribunal de instancia absolvió (o agrava la condena que recayó en instancia) el artículo 6.1 CEDH exige que el proceso ad quem se ventile con inmediación en audiencia pública, gozando el acusado de la posibilidad de defenderse ante el tribunal ${ }^{23}$. El principal motivo reside en que "el destino procesal del justiciable estaría de nuevo en juego, y tendría, por ello, que reproducirse la posibilidad de control social del procedimiento"24. Dicho con otras palabras: cada vez que estemos ante una valoración fáctica y se encuentre en juego la inocencia y/o culpabilidad del acusado, el TEDH exige esa vista pública ${ }^{25}$.

Como toda regla general esta también parece tener alguna excepción. El TEDH también ha dicho que esa audiencia pública en segunda instancia debe celebrarse siempre que en la apelación se discuta la realización de la misma conducta punible, sobre la base de pruebas que deban reproducirse en juicio oral (y no sobre la base del resto de circunstancias que pudieran dilucidarse con el simple estudio de los autos) ${ }^{26}$. Con eso parece que el TEDH se reserva un cierto margen de actuación que flexibiliza la exigencia citada a tenor de otras variables en juego, margen que ha suscitado cierta crítica de la doctrina ${ }^{27}$.

\footnotetext{
${ }^{21}$ STEDH Pakelli c. República Federal de Alemania, de 25 de abril de 1983; STEDH Axen c. República Federal de Alemania, de 8 de diciembre de 1983; STEDH Sutter c. Suiza, de 22 de febrero de 1984; y STEDH Colozza c. Italia, de 12 de febrero de 1985.

${ }^{22}$ STEDH Ekbatani c. Suecia, de 26 de mayo de 1988; y STEDH Constantinescu c. Rumanía, de 27 de junio de 2000.

${ }^{23}$ De nuevo, STEDH Ekbatani c. Suecia, de 26 de mayo de 1988 y STEDH Constantinescu c. Rumanía, de 27 de junio de 2000. Por el contrario, si el tribunal ad quem sólo valora elementos de Derecho, el artículo 6.1 CEDH no exige que se celebre nueva vista pública. Así, por ejemplo, STEDH Bazo c. España, de 16/12/2008. Por todos, LÓPEZ GUERRA, Luis: "El diálogo entre el Tribunal Europeo de derechos humanos y los tribunales españoles. Coincidencias y divergencias". Teoría y Realidad Constitucional, $n^{\circ}$ 32, 2013, p. 145 y ss.

${ }^{24}$ VIDAL ZAPATERO, José Miguel: "El derecho...", cit, p. 263.

${ }^{25}$ Vid. RODRÍGUEZ BOENTE, Sonia Esperanza: 83 argumentos que convencen al Tribunal Europeo de Derechos Humanos. Aranzadi. Cizur Menor, 2015, p. 49; En líneas generales, de la lectura de la jurisprudencia de Estrasburgo lo que realmente parece deducirse es que el precepto impone al tribunal de apelación que respete y garantice el derecho de defensa y de contradicción del acusado, concediéndole a estos efectos la imprescindible audiencia. Así lo defiende ESCALADA LÓPEZ, María Luisa; "Doble instancia e inmediación: ¿un problema resuelto?”. En Moreno Catena, Víctor (dir): Reflexiones sobre el nuevo proceso penal. Tirant lo blanch. Valencia, 2015, p. 933 y ss.

${ }^{26}$ STEDH Jan-Ake Anderson c. Suecia, de 29 de octubre de 1991; STEDH Fedje c. Suecia, de 29 de octubre de 1991; y STEDH Helmers c. Suecia, de 29 de octubre de 1991; y STEDH Michael Edward Cooke c. Austria, de 08 de febrero de 2000.

${ }^{27}$ VIDAL ZAPATERO, José Miguel: "El derecho...", cit, p. 265.
} 


\section{LAS CONDENAS A ESPAÑA POR VULNERAR LA GARANTÍA DE INMEDIACIÓN A LA LUZ DEL CONVENIO EUROPEO DE DERECHOS HUMANOS}

En lo que hace a nuestro país se debe empezar diciendo que este precepto, el artículo $6 \mathrm{CEDH}$ es el que ha ocasionado más condenas ${ }^{28}$ (y eso que España no es de los países que puedan calificarse de incumplidores sistemáticos del Convenio) ${ }^{29}$. Aquí sólo nos ocuparemos de las condenas por vulnerar la exigencia de inmediación en la segunda instancia penal, cuya configuración ha resultado ser, según el parecer doctrinal, nuestro particular "talón de Aquiles" en el sistema convencional ${ }^{30}$.

Hagamos, pues, una radiografía de conjunto de tales condenas.

Lo primero que destaca es que el Reino de España ha sido condenado quince veces en Estrasburgo. Ese guarismo puede ser sometido a interpretaciones diversas, pero una cosa queda clara: somos de los países menos condenados (tanto en general como por este motivo) $)^{31}$.

El segundo aspecto relevante es que catorce de esas condenas se incardinan en la vulneración del artículo $6.1 \mathrm{CEDH}^{32}$ y una se incardina en la vertiente procesal del artículo $3 \mathrm{CEDH}$ (Portu Juanenea) ${ }^{33}$. Esto presenta una particular explicación por el caso de autos que luego se apuntará.

28 Debe recordarse que el artículo 6.1 CEDH goza de un contenido amplísimo que el TEDH no ha hecho
sino ampliar paulatinamente. Por ello comprende desde condenas por indefensión hasta por dilaciones
indebidas, pasando por falta de motivación en las resoluciones judiciales internas, por falta de
imparcialidad del juzgador, o por ruptura del principio de seguridad jurídica. A título de ejemplo valgan
la STEDH Otegi Mondragón y otros c. España, de 6 de noviembre de 2018, y la STEDH Arrózpide
Sarasola y otros c. España, de 23 de octubre de 2018. En ambas el TEDH estima la vulneración del
artículo 6.1 CEDH, aunque por motivos diferentes (en el primero por quiebra de la imparcialidad; y en el
segundo por quiebra de la seguridad jurídica). Es sugerente el trabajo de DELGADO DEL RINCÓN,
Luis; "El TEDH y las condenas a España por la vulneración del derecho a ser juzgado en un plazo
razonable: las dificultades para alcanzar una duración óptima de los procesos judiciales", Teoría y
Realidad Constitucional, no 42 (2018), pp. 569-590.
29 Vid. MATIA PORTILLA, Francisco Javier: "Examen de las sentencias del Tribunal de Estrasburgo que
afectan al Reino de España", Teoría y Realidad Constitucional, no 42, 2018, pp.273-310; y DÍAZ
CREGO, Ma; "La jurisprudencia del Tribunal Europeo de derechos humanos en torno a España: una
historia de acuerdos y desencuentros"; En García Roca, Javier; y Santolaya Machetti, Pablo; (coords); La
Europa de los Derechos. El Convenio Europeo de Derechos Humanos, CEPC, Madrid, 2014 (3 $3^{\mathrm{a}}$ edición),
p. 807. Datos recientes y contrastados pueden verse en ECHR: Overview 1959-2017, 2018 (en línea:
https://www.echr.coe.int/.../Overview_19592016_ENG.pdf, consultado el 26 de octubre de 2018).
30 Vid. DÍAZ CREGO, María: "La jurisprudencia...", cit, p. 807; y MATIA PORTILLA, Francisco Javier:
"Examen...", cit., en prensa. 31 Vid. en ECHR: Overview 1959-2017, 2018, p. 9 (en línea: https://www.echr.coe.int/.../Overview_19592016_ENG.pdf, consultado el 26 de octubre de 2018).

32 Sobre el particular puede verse PÉREZ SOLA, Nicolás: "El contenido del derecho a un proceso con todas las garantías en la segunda instancia penal a la luz de la jurisprudencia del TEDH", Teoría y Realidad Constitucional, $n^{\circ}$ 42, 2018, pp. 317-393.

${ }^{33}$ Es jurisprudencia constante del TEDH observar en el artículo 3 CEDH dos vertientes. Una material, donde se prohíbe absolutamente todo tipo de torturas y cualesquiera malos tratos, tratos inhumanos y/o degradantes; y otra procesal, donde se exige que las autoridades nacionales investiguen oficial y eficazmente todas las denuncias de tratos de ese tenor. De no hacerse, se vulnera el precepto. Vid. SALADO OSUNA, Ana: "Los tratos prohibidos en el artículo 3 del CEDH”. En García Roca, Javier; y Santolaya Machetti, Pablo; (coords); La Europa de los Derechos el Convenio Europeo de Derechos Humanos, CEPC, Madrid, 2014 (3 $3^{\text {a }}$ edición), pp. 85-112; y SANTAMARÍA ARINAS, René; y BOLAÑO PIÑEIRO, María del Carmen: "Prohibición de la tortura”. En Lasagabaster Herrarte, Iñaki (dir.): 
El tercer aspecto es que todas ellas son, claro queda a estas alturas, condenas en procesos penales. Así, los casos Igual Coll; Marcos Barrios; García Hernández; Almenara Álvarez; Lacadena Calero; Valbuena Redondo; Serrano Contreras; Vilanova Goterris y Llop García; Nieto Macero; Román Zurdo; Sainz Casla; Porcel Terribas; Gómez Olmeda; y Atutxa Mendiola ${ }^{34}$, se refieren a condenas, efectivamente, en el marco de procesos penales, donde se acabó por no respetar el artículo 6.1 CEDH a juicio del TEDH. Y uno -y sólo uno de momento- incardinado en la vertiente procesal del artículo 3 CEDH, también se sustancia en el marco de un proceso penal.

El cuarto aspecto es el arco temporal que abarcan las condenas. El Reino de España no ha sido condenado "desde siempre". En ese sentido conviene recordar que la primera condena recae en 2009 y la última en 2017, por lo que la totalidad de las condenas se dictan en menos de una década, a casi una por año ${ }^{35}$.

El quinto aspecto que destaca es el que se refiere a los Tribunales afectados. Así, diez de esas condenas afectan a sentencias de Audiencias Provinciales y cuatro a sentencias del Tribunal Supremo que resolvían recurso de casación. Huelga decir que el amparo no fue concedido en ningún caso, de ahí que el recurso llegase hasta la jurisdicción de Estrasburgo. Conviene retener, no obstante, que aunque es cierto que los datos muestran que existe un problema, no es menos cierto que nuestros tribunales lo han intentado paliar aplicando y no eludiendo las exigencias convencionales ${ }^{36}$.

En sexto lugar, las condenas incardinadas en el artículo 6.1 CEDH dan pie a establecer una suerte de íter procesal que desemboca en las mismas. Lo primero que sucede en todos los casos es una condena en apelación cuando se absolvió al reo en instancia. Después se observa la inadmisión a trámite del recurso de amparo correspondiente por parte de nuestro Tribunal Constitucional; tales inadmisiones comparten un mismo fundamento jurídico: según el criterio del Juez de la Constitución lo que el tribunal de apelación revisa son elementos jurídicos y no fácticos (lo que como es sabido puede hacer; ergo, a su parecer, no se lesiona el artículo 24.2 CE) ${ }^{37}$. Así, el

Convenio Europeo de Derechos Humanos: Comentario Sistemático. Civitas. Madrid, 2015 (3ª edición), pp. 54-95.

${ }^{34}$ Los casos fueron decididos, respectivamente, por la STEDH de 10 de marzo de 2009; la STEDH de 21 de septiembre de 2010; la STEDH de 16 noviembre de 2011; la STEDH de 25 de octubre de 2011; la STEDH de 13 de diciembre de 2011; la STEDH de 20 de marzo de 2012; la STEDH de 22 de noviembre de 2011; la STEDH de 27 de noviembre de 2012; la STEDH de 8 de octubre de 2013; la STEDH de 8 de octubre de 2013; y la STEDH de 12 de noviembre de 2013; la STEDH de 8 de marzo de 2016; la STEDH 29 de marzo de 2016; y la STEDH de 13 de junio de 2017.

35 Por el contrario, cuatro demandas no finalizaron en condena. Hablamos de los casos Naranjo Acevedo (STEDH de 23 de octubre de 2018); Vilches Coronado (STEDH de 13 de marzo de 2018); Pérez Martínez (STEDH de 23 de febrero de 2016); y Hernández Royo (STEDH de 20 de septiembre de 2016). Es verdad, no obstante, que en el plazo de tres años (2008-2011) se sucedieron hasta seis condenas. Vid. GÓMEZ DE LIAÑO FONSECA HERRERO, Marta: "La supuesta garantía de la inmediación en la segunda instancia penal española: seis sentencias condenatorias del TEDH en menos tres años". En Revista General de Derecho Europeo, $n^{\circ} 27,2012$, pp. 1-25.

${ }^{36}$ A lo cual también coadyuva el Tribunal Constitucional, quien desde el año 2002 integró el canon convencional. Vid. PÉREZ SOLA, Nicolás; "El contenido...", cit, p. 456 y ss. También parece que Ley 41/2015 ha ayudado a tal extremo, habiendo "devuelto el recurso de casación a su dimensión natural". Así lo expresa MATIA PORTILLA, Francisco Javier: "Examen...", cit., en prensa.

37 Algunos sectores doctrinales sostienen que "la distinción entre cuestiones de hecho y cuestiones jurídicas no tiene futuro alguno, discusión que su juicio "fundamentalmente sirve para confundir y oscurecer la realidad". Vid. MILANS DEL BOSCH, S; "La segunda instancia penal generalizada tras la reforma de la LECrim...y necesidad de celebración de la vista", Actualidad Jurídica Aranzadi, $n^{\circ}$ 913, 2015, p. 1. 
recurrente llega a Estrasburgo, litiga y el TEDH le da la razón con una interpretación diametralmente opuesta: entiende este que los tribunales de apelación revisaron de nuevo elementos fácticos (nueva valoración de prueba y de testimonios, sobre todo) y que dicha revisión se realizó sin vista pública, lo cual, siguiendo su propia jurisprudencia, vulnera el artículo 6.1 $\mathrm{CEDH}^{38}$.

Finalmente, cabe destacar un par de apuntes respecto al fallo. Primero, todas las resoluciones, sin excepción, se dictaron por unanimidad. Si acaso destaca la única discrepancia -que no es tal- en el caso García Hernández, mediante la opinión concurrente del Juez Zupančič, quien consideró que "habría que invitar insistentemente al Gobierno español a adoptar una legislación que permitiera un nuevo proceso, a petición de cualquier demandante, cuando el Tribunal Europeo de derechos humanos hubiera comprobado una violación del derecho a un proceso equitativo". Segundo, la materialización de aquél. Y es que en todas ellas establece, una vez condenado el Estado, el pago de una indemnización (el conocido mecanismo de la satisfacción equitativa), en concepto de daños morales y en concepto de gastos y costas procesales. Las cantidades en ningún caso se alejan de lo razonable, incluso a veces son meramente testimoniales (como en el caso Atutxa Mendiola, que el TEDH fija en "1 euro" por daño moral y en 600 euros "de manera conjunta para todos los demandantes").

En lo que hace a la condena incardinada en el artículo $3 \mathrm{CEDH}$, resaltar que nos encontramos ante uno de los aspectos más novedosos respecto a la vulneración de la inmediación en la segunda instancia (se habla del caso Portu Juanenea y Sarasola Yarzabal $^{39}$ ). La diferencia con el resto de condenas por lesionar este precepto estriba, precisamente, en que el TEDH aplica la doctrina sentada al hilo de los casos relacionados con el artículo 6.1 CEDH y no la deducida de aquél. El motivo es bastante obvio: los tribunales internos investigaron de forma eficaz y suficiente las denuncias de torturas, pero el tribunal ad quem lo hizo sin respetar los criterios de Estrasburgo, porque valoró de nuevo elementos probatorios personales sin celebrar un nuevo juicio donde se pudiera escuchar a todas las partes.

Aplicando criterios jurisprudenciales precedentes, el TEDH observa que "el Tribunal Supremo no se limitó a efectuar una interpretación diferente de las pruebas documentales, asimismo reevaluó la credibilidad de los testimonios de ambos demandantes, querellantes en el procedimiento interno, así como la de otros testigos (...). Esta nueva valoración de las pruebas de carácter personal, sin una valoración

\footnotetext{
38 Obviamente, no se vulnera el principio de inmediación cuando los acusados, pudiendo intervenir, deciden no hacerlo. Eso es precisamente lo que sucede en el caso Vilches Coronado c. España (STEDH de 13 de marzo de 2018). En líneas generales, "sólo si el debate de planteado en la segunda instancia versa exclusivamente sobre estrictas cuestiones jurídicas no resulta necesario oír personalmente al acusado en un juicio público, pues dicha audiencia ninguna incidencia podría tener en la decisión que pudiera adoptarse, y en la medida en que el debate sea estrictamente jurídico, la posición de la parte puede entenderse debidamente garantizada por la presencia de su abogado, que haría efectivo el derecho de defensa frente a los argumentos esgrimidos por la otra parte". Así lo expresa SUBIJANA ZUNZUNEGUI, Ignacio José; "El enjuiciamiento penal: quién decide, dónde se decide, cómo se decide y cómo se revisa lo decidido", Revista Aranzadi de Derecho y Proceso Penal, nº 48, 2017, p. 17.

${ }^{39}$ La condena es novedosa en este punto y, desafortunadamente, en otro más, dado que es la primera vez en la historia que España es condenada por vulnerar la vertiente material del artículo 3 CEDH (el TEDH considera que los hechos no constituyeron torturas pero sí tratos inhumanos/degradantes). Por lo demás, esta es la última de las once condenas que hasta la fecha han recaído sobre nuestro país por vulnerar la vertiente procesal del precepto. Vid. ÁLVAREZ RODRÍGUEZ, I: "España y el artículo 3 del Convenio Europeo de Derechos Humanos: un balance", Teoría y Realidad Constitucional, n 42, 2018, pp. 591-608.
} 
directa por el Tribunal Supremo y en contradicción con las conclusiones del tribunal de instancia, que tuvo la oportunidad de escuchar el testimonio de los demandantes, los acusados y de todos los testigos en una audiencia pública, fue determinante para concluir la absolución de los guardias civiles acusados” (§83). Y sigue: “(...) cuando los tribunales de apelación o de recurso revisan las pruebas de carácter personal como los testimonios de los testigos o de los acusados y llegan a conclusiones opuestas a las establecidas por la jurisdicción a quo, las exigencias de un proceso equitativo hacen indispensable la celebración de una audiencia pública ante el tribunal de apelación o de recurso, para que éste pueda tener un conocimiento directo e inmediato de dichos elementos de prueba (...)" (§93). Acto seguido, conecta tal extremo con la vertiente procesal más clásica, la anclada en el artículo $3 \mathrm{CEDH}$, toda vez que "Dichas omisiones impidieron que la jurisdicción nacional estableciera los hechos y el conjunto de las circunstancias de una forma tan completa a como podría haberlo hecho, si conforme a la obligación que demanda el artículo 3 del Convenio hubiera sometido el caso ante él a un examen escrupuloso" (§94).

La principal consecuencia del supuesto resulta palmaria: de seguir el criterio que se establece en la sentencia el trámite de audiencia pública en apelación debería realizarse en todo caso, independientemente de que en primera instancia se condenara o $\mathrm{no}^{40}$.

\section{LA REACCIÓN DE ESPAÑA ANTE LAS CONDENAS}

Las instituciones españolas siempre han procurado cumplir con las exigencias del Convenio. Esta materia se presta especialmente a comprobar si eso es cierto o no. Para responder afirmativamente, cabe traer a colación tres líneas de investigación. Dos de ellas, sostenidas en el tiempo y de largo alcance, son la discusión y formulación de propuestas y alternativas por parte de la comunidad de expertos, así como la recepción y aplicación de los criterios de Estrasburgo por parte de nuestros altos tribunales, Tribunal Constitucional y Tribunal Supremo. La tercera es la reforma de la legislación procesal de 2015, que aborda frontalmente el problema, aunque no sabemos si lo resuelve definitivamente ${ }^{41}$.

40 Vid. GOYENA HUERTA, Jaime: "La segunda instancia y la doctrina del Tribunal Europeo de Derechos Humanos. Especial referencia a la Sentencia Portu-Sarasola c. España". Revista Aranzadi Doctrinal, $n^{\circ} 4$, 2018, p. 4 y ss. Tampoco puede olvidarse lo que dijeron los Jueces discrepantes (Keller, Pastor Vilanova y Serghedis) en su opinión parcialmente disidente y parcialmente concurrente: "En nuestra opinión, existían, en este caso, elementos convincentes que hubieran permitido a la Sala apartarse de la valoración de los hechos considerados por el Tribunal Supremo. En primer lugar, el Tribunal Supremo ha procedido a una nueva evaluación de la credibilidad de las declaraciones de los demandantes y de los testimonios de tres testigos, pero sin oírlos previamente. El más Alto Tribunal ha estimado sobre todo que estos tres testigos eran parciales por sus supuestos vínculos con ETA, lo que ha dado pie a una absolución general. Ahora bien en la sentencia Lacadena Calero c. España (...), esta misma Sala ya tuvo la ocasión de condenar esta práctica del Tribunal Supremo a tenor del artículo 6 del Convenio, no sólo por su falta de conocimiento directo e inmediato de las pruebas subjetivas sino que además el recurso de casación no permite volver, en principio, sobre los hechos ya determinados por la primera instancia. En consecuencia parece ilógico que la Sala haya concluido, por una parte que, "en ausencia de prueba concluyente relativa a la finalidad de los tratos infligidos" (párrafo 84), lo que equivale a dar el mismo valor a las dos sentencias penales, y por otra, que haya sancionado la nueva (e irregular) valoración de los hechos contenida en la última. La coherencia interna de la sentencia se encuentra entonces debilitada (...)".

${ }^{41}$ Haciendo bueno el efecto absorción defendido por GARLICKI, Lech; "Judgments of the European Court of Human Rights (their structure, impact and authority)". En Carmona Cuenca, E; y García Roca, J 
Respecto a la primera cuestión, lo primero que hay que anotar es que la doctrina viene debatiendo este asunto desde hace lustros, en todo caso desde tiempos muy anteriores a la primera condena a España. La cuestión, que entronca con la naturaleza del proceso penal y con las garantías que deben rodear al mismo, gira en torno a dos posturas: la de aquellos que defienden la segunda instancia penal con todas las garantías (nuevo juicio) y la de aquellos que defienden que las garantías deben residir en primera instancia, sin perjuicio de una cierta revisión en segunda (juicio sobre el juicio $)^{42}$.

El primer sector, el que defiende una segunda instancia penal con todas las garantías, donde la cognición sea ilimitada, recuerda que nuestra legislación procesal ha sido tradicionalmente una legislación que ha regulado el recurso de apelación de forma restringida (extremo que parece haberse mantenido incluso después de la reforma de 2015). Si hubiera que resumir el problema en una frase se podría decir que el juez de apelación queda constreñido a lo declarado probado por el juez de instancia, lo cual ha sido duramente criticado, entre otros motivos porque "puede fomentar la arbitrariedad y las sentencias manipulativas" ${ }^{43}$. En consecuencia estiman necesario, a la luz del art. 24.2 CE y 6.1 CEDH, una nueva instancia con todas las garantías.

Por lo demás, este sector observa que los problemas se reproducen también en el recurso de casación. El TS no puede gravar más al recurrente si debe hacerlo valorando nuevamente pruebas personales (STS 892/2016, de 25 de noviembre). Si lo hace siguiendo una herramienta tal como las grabaciones del DVD del juicio de instancia, debe otorgar la última palabra al acusado, cumpliendo el trámite de audiencia. Si no lo hace -y hay que tener en cuenta lo que dice el Acuerdo del Pleno No Jurisdiccional de 16 de diciembre de 2012, donde recuerda que ni esa es la naturaleza de la casación ni dicho trámite se prevé legalmente en la regulación de este recurso- el amparo por el TC o, en su caso, por el TEDH, está casi garantizado.

El otro sector doctrinal recuerda que nuestro modelo de apelación no da lugar a un nuevo juicio sobre los méritos del caso, sino a un "juicio sobre el juicio" ya consumado ante el tribunal a quo ${ }^{44}$. Es decir, ese segundo proceso es y debe ser necesariamente un proceso de cognición limitada. Reconociendo que un modelo de segunda instancia penal pleno, con todas las garantías, sería más respetuoso para con el principio de inmediación y para con la doctrina de Estrasburgo sobre el derecho de defensa, no es menos cierto que suscitaría otro tipo de problemas, no menores y de diversa índole (de fondo, de forma, económicos, funcionales, etc) ${ }^{45}$. En definitiva, se produce un control del juicio realizado en instancia, revisando la justificación y

(eds.); ¿ ¿Hacia una globalización de los derechos? El impacto de las sentencias del Tribunal Europeo y de la Corte Interamericana. Aranzadi. Cizur Menor, 2017, p. 67.

${ }^{42}$ Vid. TOMÉ GARCÍA, José Antonio: Recurso de apelación contra sentencias en el proceso penal. Colex. Madrid, 2013, p. 13 y ss.

${ }^{43}$ Vid. GIMENO SENDRA, Vicente: "El derecho a un proceso con todas las garantías y la inmediación del tribunal ad quem en la valoración de la prueba de carácter personal". En Gimeno Sendra, Vicente (et. al); Los derechos fundamentales y su protección jurisdiccional. Edisofer. Madrid, 2018, p. 472 y ss.

${ }^{44}$ Vid. CABEZUDO RODRÍGUEZ, Nicolás: "Acceso a la justicia y garantías del debido proceso". En Rey Martínez, Fernando (dir.): Los Derechos Humanos en España. Un balance crítico. Tirant lo blanch. Valencia, 2015, pp. 176-196.

${ }^{45}$ Vid. MONTERO AROCA, José: Principios..., cit., p. 179 y ss. 
argumentación que el juez realiza de las pruebas de cargo y descargo allí planteadas. Lo cual se parece mucho a una "auditoria jurisdiccional" ${ }^{46}$.

Uno de los aspectos que destaca con luz propia es aquella solución podríamos llamar intermedia de la reproducción audiovisual de las pruebas penales, visionando en apelación las grabaciones del juicio de instancia. Que es un asunto realmente complejo lo muestra tanto la división doctrinal como el diferente criterio de los altos tribunales ${ }^{47}$. Mientras que ha sido permitida por el TC -no sin someterla a las garantías de audiencia pública, concediendo trámite de audiencia a la defensa, así como a contradicción y publicidad (por todas de una lista abundante: STC 105/2014)- ha sido rechazada por el TEDH, como bien sabemos en el Caso Gómez Olmeda ${ }^{48}$, donde se nos insiste en que el tribunal ad quem no puede hacer lo que hace, (condenar sin celebrar vista donde examinar personal y directamente el testimonio del inculpado $)^{49}$.

Nuestros altos tribunales, esto es, Tribunal Constitucional y Tribunal Supremo, también han tenido una reacción que merece ser comentada.

Respecto a la jurisprudencia constitucional, y aunque se discute mucho sobre el contenido y alcance de la interpretación en general de nuestro catálogo de derechos fundamentales ex artículo $10.2 \mathrm{CE}^{50}$, es sabido que en esta materia el Tribunal Constitucional viene aplicando el canon interpretativo de Estrasburgo desde hace al menos quince años; concretamente, desde la STC 167/2002, con el consiguiente otorgamiento del amparo en los diferentes procesos ${ }^{51}$, y con escasa discrepancia en el seno del Tribunal ${ }^{52}$.

\footnotetext{
${ }^{46}$ Vid. DÍAZ VEIGA, María José; "La desacralización de la inmediación y la doble instancia penal", El Notario, 14 de julio de 2016.

47 GIMENO SENDRA, Vicente: "El derecho...", cit, passim; y CABEZUDO RODRÍGUEZ, Nicolás: "Acceso a...", cit, passim, se muestran a favor. MONTERO AROCA, José: Principios..., cit, pássim, lo hace en contra. ALCÁCER GUIRAO, Rafael, en El derecho..., cit, pássim, se encuentra en posición intermedia, Por su parte, TOMÉ GARCÍA destaca que no se podría revocar en apelación una sentencia absolutoria en instancia tras valorar las pruebas personales sólo mediante el visionado de la grabación de instancia. Vid. TOMÉ GARCÍA, José Antonio: Recurso..., cit. p. 50 y 51.

${ }^{48}$ STEDH Gómez Olmeda c. España, de 29 de marzo de 2016.

${ }^{49}$ Vid. SÁNCHEZ ROMERO, Rosario: La garantía..., cit, p. 110 y 111.

${ }^{50}$ Así, para Matia Portilla, el TC tendría en los criterios hermenéuticos internacionales un criterio más para concretar el alcance de los derechos fundamentales. Para Canosa Usera no acaba de resultar convincente que el TC reitere "sin desmayo" que el CEDH no integra su canon de enjuiciamiento a la vez que se vincula a la interpretación que hace del mismo el TEDH. Vid. MATIA PORTILLA, Francisco Javier: Los tratados internacionales y el principio democrático. Marcial Pons. Madrid, 2018, p. 115 y ss; y CANOSA USERA, Raúl: El control de convencionalidad. Civitas-Thomson Reuters. Cizur Menor, 2015, p. 97 y ss; para Arzoz Santisteban los criterios derivados del precepto cumplen con una función actualizadora y coordinadora de los derechos fundamentales, sin que en ningún caso quepa deducir de los mismos nuevos derechos. Vid. ARZOZ SANTISTEBAN, Xabier. La concretización y actualización de los derechos fundamentales. CEPC. Madrid, 2014, p. 177 y ss.

51 Por ejemplo, las SSTC 232/2002, 134/2007, 184/2009, 45/2011, 142/2011. 201/2012, 88/2013, 105/2016, 172/2016, 125/2017, 146/2017, 36/2018, y 37/2018. En algunas de ellas (184/2009, 45/2011, 142/2011), el Tribunal añade una garantía adicional a la inmediación, cual es la audiencia personal del acusado. Vid. ALCÁCER GUIRAO, Rafael: El derecho..., cit, p. 83. Para algunos sectores, el TC podría haber actuado en alguno de esos casos de forma demasiado garantista, toda vez que llegó a decir que debía escucharse en apelación al acusado incluso si sólo se estaban discutiendo elementos jurídicos (STC 184/2002), lo cual rectificó posteriormente (STC 45/2011). Vid. RODRÍGUEZ BOENTE, Sonia Esperanza: 83 argumentos..., cit., p. 48.

52 En dicha resolución, en la STC 167/2002, el Magistrado D. Roberto García-Calvo emitió voto particular donde se manifestaba contrario a aplicar de tal forma el canon convencional. Por un lado, porque observaba que la doctrina del Tribunal Europeo de Derechos Humanos no implica en todo caso la
} 
Son muchas las resoluciones que el Tribunal, desde aquella, ha dictado en ese sentido $^{53}$. De todas ellas se pueden extraer algunas conclusiones de relevancia, sobre todo las que ayudan a responder el interrogante de hasta qué punto se puede revisar la prueba de instancia en apelación. Tal cosa podría suceder básicamente en tres situaciones $^{54}$. Primero, según el TC no se puede condenar a quien fue absuelto (o no se puede agravar la condena del condenado) con una nueva valoración de las pruebas personales si no se vuelve a practicar dicha prueba en apelación. Segundo, la prueba documental, per se, puede valorarse de tal suerte que conduzca a la condena del absuelto en instancia (o a la agravación de la condena del ya condenado), dado que la garantía de inmediación es la misma en ambos procesos. Tercero, cabe revisar cuestiones sustantivas no procesales y acabar condenando a quien fue absuelto (o agravar la condena del condenado), tales como errores a la hora de subsumir en el tipo el ilícito, o los elementos de la culpabilidad, por poner dos ejemplos.

En fin, la última línea de la jurisprudencia constitucional no parece haber cambiado mucho de criterio. Por citar una de las últimas resoluciones, cabe traer a colación la STC 37/2018, de 23 de abril, donde sostiene que: "el respeto a los principios de publicidad, inmediación y contradicción, que forman parte del contenido del derecho a un proceso con todas las garantías (art. 24.2 CE), impone inexorablemente que toda condena articulada sobre pruebas personales se fundamente en una actividad probatoria que el órgano judicial haya examinado directa y personalmente en un debate público, en el que se respete la posibilidad de contradicción" (FJ 6). El criterio ha sido reiterado en la STC 59/2018, de 4 de junio, la resolución más reciente encontrada a la fecha de cierre del presente trabajo, donde se ampara al recurrente aplicando el canon convencional.

Respecto al Tribunal Supremo, también ha recepcionado el criterio del TEDH, tal y como se observa en jurisprudencia reciente y no tan reciente (verbigracia, en las SSTS 493/2015, de 22 de julio; 497/2015, de 24 de julio; 1002/2016, de 19 de enero de 2017) ${ }^{55}$. Conviene recordar aquí la STS 5679/2012, de 19 de julio, donde dijo tres cosas a tener en cuenta. La primera es que la legislación procesal penal española no negaba que se practicase prueba en apelación, lo que sucede es que resulta restringida a tenor del artículo 790.3 LECrim $^{56}$. Por eso no se puede dar carta de naturaleza a la práctica

necesidad de celebrar vista pública, ni que el recurrente absuelto en la instancia deba ser necesariamente oído en la apelación. Por otro, porque la distinta valoración que hace el tribunal de apelación no proviene de practicar prueba sin inmediación "sino la expresión de un criterio jurídico opuesto acerca de la existencia de la lesión del derecho fundamental invocado como vulnerado, lo que tuvo como consecuencia la posibilidad de tomar en consideración pruebas objetivamente incriminatorias que en la instancia no se utilizaron para pronunciarse sobre la culpabilidad de los acusados por entender el Juez de forma errónea, a juicio de la Audiencia, que eran constitucionalmente ilícitas, y por ello inválidas" (apartado 3 del Voto Particular).

53 Se remite de nuevo al estudio de PÉREZ SOLA, Nicolás; "El contenido...", cit, p. 456 y ss.

${ }^{54}$ Vid. SUBIJANA ZUNZUNEGUI, Ignacio José; "El enjuiciamiento...", cit, pp. 17 y 18.

55 De importancia capital es la STS 1322/2009, de 30 de diciembre, por considerar que la inmediación es una "técnica de formación de la prueba, que se escenifica ante el Juez, pero no es ni debe ser considerada como un método para el convencimiento del Juez”, lo cual tiene dos efectos: le impide alegar la misma para evitar motivar la resolución y hace del control casacional una instancia perfectamente válida para revisar la valoración de la prueba. Vid. RIFÁ SOLER, José María; y RICHARD GONZÁLEZ, Manuel; El Proceso..., cit., p. 114 y 115.

${ }^{56}$ Artículo 790.3 LeCrim: "En el mismo escrito de formalización podrá pedir el recurrente la práctica de las diligencias de prueba que no pudo proponer en la primera instancia, de las propuestas que le fueron indebidamente denegadas, siempre que hubiere formulado en su momento la oportuna protesta, y de las admitidas que no fueron practicadas por causas que no le sean imputables". 
generalizada de prueba en segunda instancia (mucho menos exigirla). La segunda es que si ese es el criterio de Estrasburgo, y lo es, lo que se está haciendo es exigir que se celebre un nuevo juicio, con repetición oral, vista pública y práctica de prueba, lo que devalúa la primera instancia. Y la última, derivada de esta pero no menos importante: tales exigencias alteran sustancialmente el sistema procesal español de recursos. Parte de la doctrina más autorizada entiende que el Tribunal Supremo está en lo cierto, y que precisamente lo que resulta necesario es una reforma del sistema de recursos si queremos adecuarnos a los patrones convencionales dictados al socaire del artículo 6.1 $\mathrm{CEDH}^{57}$.

Quizá el principal problema se plantea en torno al recurso de casación. Efectivamente, es doctrina firme del Tribunal Supremo que en casación no puede condenarse a quien ha sido absuelto en instancia (o agravar su condena de haber sido condenado) si ello supone modificar la convicción relacionada con los hechos probados en aquellos juicios. Para ello se requiere, dirá, audiencia previa al acusado. Y el problema aparece cuando se aprecia que en la sustanciación del recurso de casación la legislación que lo regula no contempla dicho trámite. Así que Estrasburgo exige la adopción de una medida que nuestra legislación no contempla directamente (sin perjuicio de lo que ahora se dirá), extremo que recordó el propio Tribunal Supremo (Sala Segunda) en su Acuerdo No Jurisdiccional, de 19 de diciembre de 2012, donde literalmente acuerda que: "La citación del acusado recurrido a una vista para ser oído personalmente antes de la decisión del recurso ni es compatible con la naturaleza de la casación, ni está prevista en la ley". ${ }^{58}$

Finalmente, no puede obviarse la reforma legislativa acometida en 2015 en nuestra legislación procesal penal, reforma desbrozada hasta en siete leyes diferentes y no consecutivas. Ya puede adivinarse que ni la forma de acometer las reformas ni la técnica legislativa de buena parte de ellas han concitado los apoyos doctrinales ${ }^{59}$. Independientemente de que afectan a diversas cuestiones procesales de importancia ${ }^{60}$, en lo que hace al objeto del presente trabajo destaca la modificación de la letra de los artículos 790.2 y 792.2 LeCrim.

La dicción literal del artículo 790.2 LeCrim reza así: "El escrito de formalización del recurso se presentará ante el órgano que dictó la resolución que se impugne, y en él se expondrán, ordenadamente, las alegaciones sobre quebrantamiento de las normas y garantías procesales, error en la apreciación de las pruebas o infracción de normas del ordenamiento jurídico en las que se base la impugnación. El recurrente también habrá de fijar un domicilio para notificaciones en el lugar donde tenga su sede la Audiencia. Si en el recurso se pidiera la declaración de nulidad del juicio por infracción de normas o garantías procesales que causaren la indefensión del recurrente, en términos tales que no pueda ser subsanada en la segunda instancia, se citarán las normas legales o constitucionales que se consideren infringidas y se expresarán las

\footnotetext{
${ }^{57}$ Vid. LÓPEZ GUERRA, Luis: "El diálogo...", cit, p. 147.

${ }^{58}$ Vid. SUBIJANA ZUNZUNEGUI, Ignacio José; "El enjuiciamiento...", cit, p. 18.

${ }^{59}$ Por todos, ALONSO-CUEVILLAS SAYROL, Jaume: "El nuevo proceso penal: valoración crítica de las reformas procesales de 2015”. En Alonso-Cuevillas Sayrol, Jaume (dir): El nuevo proceso penal tras las reformas de 2015. Atelier. Barcelona, 2016, p. 20 y ss.

${ }^{60}$ Nos referimos, entre otras, a la generalización de la segunda instancia o a la ampliación de motivos que permiten plantear el recurso de revisión. Vid. MARCHENA GÓMEZ, Manuel; Y GONZÁLEZCUÉLLAR SERRANO, Nicolás: La reforma..., cit, p. 533 y ss; y BELLIDO PENADÉS, Rafael: "Generalización de..., cit; y "Revisión penal y..., cit.
} 
razones de la indefensión. Asimismo, deberá acreditarse haberse pedido la subsanación de la falta o infracción en la primera instancia, salvo en el caso de que se hubieren cometido en momento en el que fuere ya imposible la reclamación. Cuando la acusación alegue error en la valoración de la prueba para pedir la anulación de la sentencia absolutoria o el agravamiento de la condenatoria, será preciso que se justifique la insuficiencia o la falta de racionalidad en la motivación fáctica, el apartamiento manifiesto de las máximas de experiencia o la omisión de todo razonamiento sobre alguna o algunas de las pruebas practicadas que pudieran tener relevancia o cuya nulidad haya sido improcedentemente declarada".

Por su parte, la dicción literal del artículo 792.2 LeCrim establece que: "La sentencia de apelación no podrá condenar al encausado que resultó absuelto en primera instancia ni agravar la sentencia condenatoria que le hubiera sido impuesta por error en la apreciación de las pruebas en los términos previstos en el tercer párrafo del artículo 790.2. No obstante, la sentencia, absolutoria o condenatoria, podrá ser anulada y, en tal caso, se devolverán las actuaciones al órgano que dictó la resolución recurrida. La sentencia de apelación concretará si la nulidad ha de extenderse al juicio oral y si el principio de imparcialidad exige una nueva composición del órgano de primera instancia en orden al nuevo enjuiciamiento de la causa".

De la conjunción de los principios arriba referidos parece que la reforma opta por una solución intermedia entre la opción del nuevo juicio y la opción del juicio sobre el juicio (aunque quizá algo escorada hacia esta segunda opción).

Para un sector doctrinal, con la nueva redacción de ambos preceptos "la cuestión queda definitivamente resuelta", porque el tribunal ad quem no puede ya revocar la sentencia apelada para valorar de forma distinta la prueba del juicio oral y dictar sentencia en sentido diferente. Entonces, ¿qué puede hacer? ¿Puede anular la valoración hecha en el proceso a quo? Sí. ¿Puede sustituir la valoración realizada tribunal a quo? $\mathrm{No}^{61}$.

En línea parecida, y haciendo un repaso por los modelos ideales que tenía el legislador español como alternativa (desde el modelo anglosajón de prohibir el recurso frente a la sentencia absolutoria por el desacuerdo de la acusación con la determinación de los hechos hasta el modelo alemán, de apelación plena, reproduciéndose por completo la prueba en nuevo juicio en segunda instancia) se ha dicho que la reforma de nuestra legislación es más consecuente tanto con la jurisprudencia del Tribunal Supremo como con la garantía de la inmediación. Sería, dicho con sus propias palabras "en lugar de pretender cuadrar el círculo, salir de ese círculo", permitiendo la anulación de la sentencia al reenviar el asunto al tribunal a quo para que se subsane el defecto ${ }^{62}$.

La comunidad de expertos no es unánime. Una de las voces críticas recuerda que con la solución dada por la reforma se repetirían pruebas ya practicadas, lo cual le restaría eficacia por quedar condicionada y afectada por la resultante del primer juicio. Además ese nuevo juicio dilataría en el tiempo el proceso quizá en exceso ${ }^{63}$. Propone una solución parecida pero diferente. Lo primero que debería hacer el tribunal de

\footnotetext{
${ }^{61}$ Defiende esta postura HERRERO ÁLVAREZ, Sergio: "El derecho de defensa en el proceso penal español: una visión práctica de sus novedades y dificultades”. En Roca Martínez, José María (dir): El proceso penal en ebullición, Atelier, Barcelona, 2017, p. 39; también SUAU MOREY, Jaime: Recurso de apelación penal. Juruá Editorial. Lisboa, 2017, p. 37.

${ }^{62}$ Vid. MARCHENA GÓMEZ, Manuel; y GONZÁLEZ-CUÉLLAR SERRANO, Nicolás: La reforma..., cit, pp. 536 y 537.

${ }^{63}$ Esta es la visión de SÁNCHEZ ROMERO, Rosario: La garantía..., cit, p. 118 y ss.
} 
apelación es reproducir la grabación del juicio de instancia. A partir de ahí, decidir qué pruebas personales deberían practicarse en segunda instancia, fijando concreta $\mathrm{y}$ expresamente lo que induce a error y/o duda. El siguiente paso sería citar de oficio en vista pública y contradictoria a todos los sujetos necesarios para esclarecer esos hechos, especialmente al acusado. Lo que realmente garantiza la reforma, dirán, son otros institutos tales como la contradicción, el derecho a la defensa y el derecho a la presunción de inocencia, no tanto la inmediación, porque el juicio se vuelve irrepetible, en el sentido de que la inmediación bien entendida se agotaría en primera instancia (la prueba caduca con la práctica de la misma). En una línea parecida, otros autores recuerdan que la misma inmediación en segunda instancia que en primera instancia es imposible por definición, perdiéndose la fiabilidad y la autenticidad. Lo menos malo, reflexionan sin considerarlo un método del todo aceptable, sería visionar la grabación de instancia y celebrar nueva vista en apelación ${ }^{64}$.

\section{CONCLUSIONES}

De lo dicho hasta aquí podemos señalar algunas reflexiones finales a modo de conclusión, cuestiones provisionales y sometidas a quienes saben de veras de estas cuestiones.

En primer lugar, queda demostrado que la inmediación es una garantía procesal reconocida tanto en el ordenamiento interno como en el ordenamiento internacional. Respecto a este último, destaca con luz propia el sistema implementado por el Convenio Europeo de Derechos Humanos e interpretado por la jurisprudencia del Tribunal Europeo de Derechos Humanos. Este ha afirmado en jurisprudencia reiterada que el artículo 6 CEDH (derecho al proceso debido/derecho al juicio justo) exige el cumplimiento de la garantía de inmediación en la segunda instancia penal, tanto por los bienes en juego como por la entidad y gravedad de los castigos aparejados.

En segundo lugar, en dicha interpretación destaca una regla general que se aplica a todos los Estados miembros: si un Tribunal interno condena en apelación cuando en instancia se absolvió (o agrava la condena dictada allí) revisando de nuevo bien elementos fácticos, bien elementos fácticos y jurídicos, y lo hace sin garantizar la inmediación, y a ello se le suma que posteriormente ningún otro tribunal interno "superior" pone remedio, Estrasburgo condenará por vulnerar el artículo 6.1 CEDH. Es jurisprudencia constante desde los años ochenta del pasado siglo y no parece que tenga visos de cambiar.

En tercer lugar, aplicando dicho criterio España ha resultado condenada hasta quince veces. Catorce de esas condenas vienen por quebrar el artículo 6.1 CEDH, al no observarse la inmediación en la segunda instancia penal. Y una, por quebrar la vertiente procesal del artículo $3 \mathrm{CEDH}$ en base al mismo motivo. Las catorce condenas presentan una serie de rasgos comunes que pueden ser resumidos en una suerte de "condena-tipo", parámetro básico que puede resultar muy útil para anticipar posteriores condenas: primero nuestro tribunal interno condena en segunda instancia (o agrava la condena ya dictada) revisando de nuevo elementos fácticos sin inmediación; después, el afectado recurre esta decisión, algunas veces en recurso de casación, las más de las veces en recurso de amparo. Así, el asunto acaba llegando al Tribunal Constitucional, que inadmite a trámite el recurso (normalmente, porque entiende que la jurisdicción

\footnotetext{
${ }^{64}$ Los límites vendrían del artículo 790.3 LeCrim arriba referido. Vid. ALCÁCER GUIRAO, Rafael: El derecho..., cit, p. 88 y ss.
} 
ordinaria ha revisado elementos jurídicos y no fácticos en aquélla). Finalmente, el litigio llega a Estrasburgo, y el TEDH condena a España porque interpreta que, cuanto menos, se han revisado de nuevo elementos fácticos en la apelación, cosa que no puede hacerse sin inmediación según su propia doctrina.

La condena incardinada en el artículo 3 CEDH va incluso un poco más allá, porque en primera instancia se había condenado a los acusados y en segunda se les había absuelto. Aun así, el TEDH acabó sentenciando la condena. La especial idiosincrasia del caso puede explicar tal extensión del límite, que en cualquier caso deberá esperar a ser confirmado o no por jurisprudencia posterior.

En cuarto lugar, destaca la reacción que ha tenido España. Y esa reacción trasluce la actitud de un Estado que demuestra, con todas las taras y tachas que se quieran, que cree de veras en el Estado de Derecho, ya que tanto la doctrina como nuestros altos tribunales, así como el legislador, intentan aportar soluciones al problema para que no sigamos siendo condenados.

La doctrina, en una discusión que viene de largo y que se debate entre el nuevo juicio y el juicio sobre el juicio. Los altos tribunales, el Tribunal Constitucional y el Tribunal Supremo, reconociendo y aplicando el canon convencional, sin dejar desamparado al justiciable (si se quiere, con un punto más de crítica en la doctrina del segundo, fundamentalmente derivada de la llamada de atención que hace sobre el recurso de casación). Y el legislador porque en el año 2015 se reforma la legislación procesal penal justamente para abordar la solución a este problema, solución que podríamos llamar "de compromiso" y que se sitúa entre las dos aguas arriba referidas (la segunda instancia como juicio sobre el juicio/la segunda instancia como nuevo juicio). El balance que la misma merezca sólo podrá hacerse una vez se observe su aplicación a lo largo y ancho de la práctica forense.

\section{BIBLIOGRAFÍA}

ALCÁCER GUIRAO, Rafael: El derecho a una segunda instancia con todas las garantías. Tirant lo blanch. Valencia, 2013.

ALGUACIL GONZÁLEZ-AURIOLES, Jorge: "Ponderación, proporcionalidad y margen de apreciación en la jurisdicción europea de los derechos". En Revista General de Derecho Europeo, $\mathrm{n}^{\circ}$ 25, 2011.

ALONSO-CUEVILLAS SAYROL, Jaume: "El nuevo proceso penal: valoración crítica de las reformas procesales de 2015". En Alonso-Cuevillas Sayrol, Jaume (dir): El nuevo proceso penal tras las reformas de 2015. Atelier. Barcelona, 2016.

ÁLVAREZ RODRÍGUEZ, Ignacio: "España y el artículo 3 del Convenio Europeo de Derechos Humanos: un balance". En Teoría y Realidad Constitucional, $\mathrm{n}^{\mathrm{0}}$ 42, 2018.

ANDRÉS IBÁÑEZ, Perfecto: "Sobre el valor de la inmediación (una aproximación crítica)". En Jueces para la democracia, nº 46, 2003.

ARZOZ SANTISTEBAN, Xabier: La concretización y actualización de los derechos fundamentales. CEPC. Madrid, 2014.

BELLIDO PENADÉS, Rafael: "Generalización de la segunda instancia y apertura de la casación en el Proyecto de reforma de la Ley de Enjuiciamiento Criminal de 2015". En Diario La Ley, no 8619, 2015.

- "Revisión penal y generalización de la doble instancia penal en el proyecto de reforma de la LECrim de 2015". En Diario La Ley, no 8526, 2015. 
BOTELLA SORIA, Enrique J.: "Las vulneraciones del principio de inmediación en la segunda instancia del proceso civil. Posibles soluciones". En Proceso civil: cuaderno jurídico, $\mathrm{n}^{\circ}$ 131, 2018.

CABEZUDO RODRÍGUEZ, Nicolás: "Acceso a la justicia y garantías del debido proceso". En Rey Martínez, Fernando (dir.): Los Derechos Humanos en España. Un balance crítico. Tirant lo blanch. Valencia, 2015.

CANOSA USERA, Raúl: El control de convencionalidad. Civitas-Thomson Reuters. Cizur Menor, 2015.

CARRASCO DURÁN, Manuel: El derecho a la tutela judicial efectiva sin indefensión. Aranzadi. Cizur Menor, 2018.

CASADEVALL, Josep: El Convenio Europeo de Derechos Humanos, el Tribunal de Estrasburgo y su Jurisprudencia. Tirant lo blanch. Valencia, 2012.

DELGADO DEL RINCÓN, Luis; "El TEDH y las condenas a España por la vulneración del derecho a ser juzgado en un plazo razonable: las dificultades para alcanzar una duración óptima de los procesos judiciales". En Teoría y Realidad Constitucional, $\mathrm{n}^{\circ}$ 42, 2018.

DÍAZ CREGO, María: "La jurisprudencia del Tribunal Europeo de derechos humanos en torno a España: una historia de acuerdos y desencuentros"; En García Roca, J; y Santolaya Machetti, Pablo (coords): La Europa de los Derechos. El Convenio

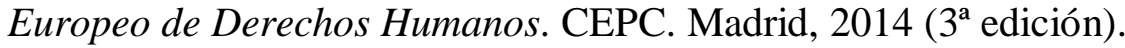

DÍAZ VEIGA, María José: "La desacralización de la inmediación y la doble instancia penal". En El Notario, de 14 de julio de 2016.

ESCALADA LÓPEZ, María Luisa: "Doble instancia e inmediación: ¿un problema resuelto?”. En Moreno Catena, Víctor (dir): Reflexiones sobre el nuevo proceso penal. Tirant lo blanch. Valencia, 2015.

ESPARZA LEIBAR, Iñaki; y ETXEBARRÍA GURIDI, José Francisco: "Derecho a un proceso equitativo". En Lasagabaster Herrarte, Iñaki (dir.): Convenio Europeo de Derechos Humanos: Comentario Sistemático. Civitas. Madrid, 2015 (3 edición).

GARBERÍ LLOBREGAT, José: Constitución y Derecho Procesal. Civitas. Cizur Menor, 2009.

GARCÍA ROCA, Javier: El margen de apreciación nacional en la interpretación del Convenio Europeo de Derechos Humanos: soberanía e integración. Cuadernos Civitas-Thomson Reuters. Madrid, 2010.

GARLICKI, Lech: "Judgments of the European Court of Human Rights (their structure, impact and authority). En Carmona Cuenca, J; y García Roca, J (eds.); ¿Hacia una globalización de los derechos? El impacto de las sentencias del Tribunal Europeo y de la Corte Interamericana. Aranzadi. Cizur Menor, 2017.

GIMENO SENDRA, Vicente: "El derecho a un proceso con todas las garantías y la inmediación del tribunal ad quem en la valoración de la prueba de carácter personal". En Gimeno Sendra, Vicente (et. al): Los derechos fundamentales y su protección jurisdiccional. Edisofer. Madrid, 2018.

GOLDSCHMIDT, James: Problemas jurídicos y políticos del proceso penal. Euros Editores. Buenos Aires, 2016 (1 ${ }^{\mathrm{a}}$ edición, Editorial Bosch, Barcelona, 1935).

GÓMEZ DE LIAÑO FONSECA HERRERO, Marta: "La supuesta garantía de la inmediación en la segunda instancia penal española: seis sentencias condenatorias del TEDH en menos tres años". En Revista General de Derecho Europeo, $n^{\circ}$ 27, 2012. 
GOYENA HUERTA, Jaime: "La segunda instancia y la doctrina del Tribunal Europeo de Derechos Humanos. Especial referencia a la Sentencia Portu-Sarasola c. España". En Revista Aranzadi Doctrinal, n 4, 2018.

HERRERO ÁLVAREZ, Sergio: "El derecho de defensa en el proceso penal español: una visión práctica de sus novedades y dificultades”. En Roca Martínez, José María (dir): El proceso penal en ebullición. Atelier. Barcelona, 2017.

LÓPEZ GUERRA, Luis: "El diálogo entre el Tribunal Europeo de derechos humanos y los tribunales españoles. Coincidencias y divergencias". Teoría y Realidad Constitucional, $\mathrm{n}^{\mathrm{o}}$ 32, 2013.

MAGRO SERVET, Vicente: "Inmediación". En Arnaldo Alcubilla, Enrique (coord.): Enciclopedia Jurídica La Ley. Wolters Kluwer. Las Rozas, 2008-2009.

MARCHENA GÓMEZ, Manuel; y GONZÁLEZ-CUÉLLAR SERRANO, Nicolás: La reforma de la Ley de Enjuiciamiento Criminal en 2015. Ediciones Jurídicas Castillo de Luna. Madrid, 2015.

MATIA PORTILLA, Francisco Javier: "Examen de las sentencias del Tribunal de Estrasburgo que afectan al Reino de España", Teoría y Realidad Constitucional, $\mathrm{n}^{\circ}$ 42, 2018.

MATIA PORTILLA, Francisco Javier: Los tratados internacionales y el principio democrático. Marcial Pons. Madrid, 2018.

MATIA PORTILLA, Francisco Javier; y ÁLVAREZ RODRÍGUEZ, Ignacio (dirs.): Informes Nacionales Europeos sobre el Tribunal Europeo de Derechos Humanos (Alemania, España, Francia, Italia, Polonia). Tirant lo blanch. Valencia, 2018.

MILANS DEL BOSCH, S; "La segunda instancia penal generalizada tras la reforma de la LECrim...y necesidad de celebración de la vista". En Actualidad Jurídica Aranzadi 913, 2015.

MILIONE, C; El derecho a la tutela judicial efectiva en la jurisprudencia del Tribunal Europeo de Derechos Humanos, Tirant lo Blanch, Valencia, 2015.

MONTERO AROCA, Juan: Principios del proceso penal. Una explicación basada en la razón. Tirant lo blanch. Valencia, 1997.

MONTOYA MELGAR, Alfredo (dir): Diccionario Jurídico. Thomson ReutersAranzadi. Cizur Menor, 2016.

MORENO CATENA, Víctor; y CORTÉS DOMÍNGUEZ, Valentín: Derecho Procesal Penal. Tirant lo blanch. Valencia, 2017.

MUÑOZ MACHADO, Santiago (dir): "Principio de inmediación". Diccionario Panhispánico del Español Jurídico. Real Academia Española-Santillana. Madrid, 2017.

NIEVA FENOLL, Jordi: "Oralidad e Inmediación en la prueba: luces y sombras". En Civil Procedure Review, vol. 1-2, 2010.

NIEVA FENOLL, Jordi: La ciencia jurisdiccional: novedad y tradición. Marcial Pons. Madrid, 2016.

PÉREZ SOLA, Nicolás: "El contenido del derecho a un proceso con todas las garantías en la segunda instancia penal a la luz de la jurisprudencia del TEDH". En Teoría y Realidad Constitucional, $\mathrm{n}^{\circ}$ 42, 2018.

RIFÁ SOLER, José María; y RICHARD GONZÁLEZ, Manuel: El Proceso Penal Práctico. Wolters Kluwer. Las Rozas, 2017.

RODRÍGUEZ BOENTE, Sonia Esperanza: 83 argumentos que convencen al Tribunal Europeo de Derechos Humanos. Aranzadi. Cizur Menor, 2015. 
RUIZ-RICO RUIZ, Gerardo; y CARAZO LIÉBANA, María José: El derecho a la tutela judicial efectiva, Tirant lo Blanch, Valencia, 2013.

SALADO OSUNA, Ana: “Los tratos prohibidos en el artículo 3 del CEDH”. En García Roca, J; y Santolaya Machetti, P (coords): La Europa de los Derechos el Convenio Europeo de Derechos Humanos. CEPC. Madrid, 2014 (3ª edición).

SÁNCHEZ ROMERO, Rosario: La garantía jurisdiccional de inmediación en la segunda instancia penal. Dykinson. Madrid, 2017.

SANTAMARÍA ARINAS, René; y BOLAÑO PIÑEIRO, María del Carmen; "Prohibición de la tortura". En Lasagabaster Herrarte, Iñaki (dir.): Convenio Europeo de Derechos Humanos: Comentario Sistemático. Civitas. Madrid, 2015 ( $3^{\text {a }}$ edición).

SUAU MOREY, Jaime: Recurso de apelación penal. Juruá Editorial. Lisboa, 2017.

SUBIJANA ZUNZUNEGUI, Ignacio José: "El enjuiciamiento penal: quién decide, dónde se decide, cómo se decide y cómo se revisa lo decidido", Revista Aranzadi de Derecho y Proceso Penal, no 48, 2017.

TAPIA FERNÁNDEZ, Isabel: La implantación generalizada de la segunda instancia penal. Presente y futuro. Civitas-Thomson Reuters. Cizur Menor, 2011.

TOMÉ GARCÍA, José Antonio: Recurso de apelación contra sentencias en el proceso penal. Colex. Madrid, 2013.

VIDAL ZAPATERO, José Miguel: "El derecho a un proceso público". En García Roca, J; y Santolaya Machetti, P (coords): La Europa de los Derechos. El Convenio Europeo de Derechos Humanos. CEPC, Madrid, 2014 (3ª edición). 